\title{
What patient factors influence bariatric surgery outcomes? A multiple regression analysis of Ontario Bariatric Registry data
}

\author{
Uri Kaplan, MD \\ Wael Zohdy, MD \\ Scott Gmora, MD \\ Dennis Hong, MD \\ Mehran Anvari, MD
}

Accepted Mar. 3, 2021

\author{
Correspondence to: \\ U. Kaplan \\ Department of General Surgery B \\ Yitzhak Rabin Blvd 21 \\ Emek Medical Center \\ Afula 1834111 \\ Israel \\ kaplanuri@gmail.com
}

Cite as: Can J Surg 2022 February 3; 65(1). doi: 10.1503/cjs.018319

\begin{abstract}
Background: As bariatric surgery evolves and gains popularity, statistical analysis of its outcomes could improve the process of decision-making and risk assessment. This study aimed to evaluate the influence of age and other factors on bariatric surgery outcomes in order to improve patient selection and outcomes.

Methods: We analyzed data from the Ontario Bariatric Registry to evaluate the influence of age and 10 other factors on early $(<90 \mathrm{~d})$ and 1-year surgical outcomes among patients aged 18 years or older who underwent laparoscopic Roux-en-Y gastric bypass (LRYGB) or laparoscopic sleeve gastrectomy (LSG) between January 2010 and May 2013. Early outcomes included composite adverse events and readmission. The 1-year outcomes included percent excess body weight loss (\% EBWL), and remission of diabetes mellitus and hypertension. We performed multiple regression analysis to identify independent variables that influenced these outcomes.
\end{abstract}

Results: We identified 3166 patients (2655 women [83.9\%] and 511 men [16.1\%], mean age $44.8 \mathrm{yr}$, mean body mass index [BMI] 48.4) who underwent LRYGB (2839 [89.7\%]) or LSG (327 [10.3\%]) over the study period and completed their 1-year follow-up. Preoperative American Society of Anesthesiologists (ASA) score and history of angina were independent variables that influenced the composite adverse event outcome. Obstructive sleep apnea was the only factor that influenced early readmission. The independent factors that influenced \%EBWL were age, type of surgery, $\mathrm{BMI}$ and baseline glycosylated hemoglobin $\left(\mathrm{HbA}_{\mathrm{lc}}\right)$ level: age was found to influence hypertension remission, and $\mathrm{HbA}_{\mathrm{cc}}$ level and obstructive sleep apnea were found to influence diabetes remission.

Conclusion: Complications after bariatric surgery can be predicted by preoperative ASA score and history of angina; patient age was not related to an increase in postoperative complications. These factors could help both surgeon and patient make appropriate surgical decisions.

Contexte : Alors que la chirurgie bariatrique évolue et gagne en popularité, l'analyse statistique de ses résultats pourrait améliorer le processus décisionnel et l'évaluation des risques. Cette étude visait à mesurer l'influence de l'âge et d'autres facteurs sur les résultats de la chirurgie bariatrique afin d'améliorer la sélection des patients et l'issue des interventions.

Méthodes : Nous avons analysé les données du Registre bariatrique de l'Ontario pour mesurer l'influence de l'âge et de 10 autres facteurs sur les résultats chirurgicaux immédiats $(<90$ j) et à 1 an chez les patients âgés de 18 ans ou plus ayant subi une dérivation gastrique Roux-en-Y (DGRY) laparoscopique ou une gastrectomie en manchon (GM) laparoscopique entre janvier 2010 et mai 2013. Les résultats immédiats incluaient un paramètre mixte composé de diverses complications et la réadmission. Les résultats à 1 an incluaient le pourcentage de masse corporelle excédentaire perdu (\% PMCE) et la rémission du diabète et de l'hypertension. Nous avons procédé à une analyse de régression multiple pour identifier les variables indépendantes ayant influé sur ces résultats.

Résultats : Nous avons recensé 3166 patients (2655 femmes [83,9\%] et 511 hommes [16,1\%], âge moyen 44,8 ans, indice de masse corporelle [IMC] moyen 48,4) ayant subi une DGRY (2839 [89,7\%]) ou une GM (327 [10,3\%]) au cours de la période de l'étude et complété une année de suivi. Le score ASA (American Society of Anesthesiologists) préopératoire et les antécédents d'angine sont les variables indépendantes qui ont influé sur le paramètre mixte des complications. L'apnée obstructive du sommeil est le seul facteur qui a influé sur le taux de réadmission. Les facteurs indépendants qui ont influé sur le \% PMCE ont été l'âge, le type de chirurgie, l'IMC et l'hémoglobine glyquée $\left(\mathrm{HbA}_{\mathrm{lc}}\right)$ au départ : l'âge a influé sur la rémission de 
l'hypertension, et l'HbA $\mathrm{A}_{\mathrm{c}}$ et l'apnée obstructive du sommeil ont influé sur la rémission du diabète.

Conclusion : Il est possible de prédire les complications de la chirurgie bariatrique en établissant le score ASA préopératoire et en relevant les antécédents d'angine; l'âge des patients n'a pas été en lien avec une augmentation des complications postopératoires. Ces facteurs pourraient aider le chirurgien et son patient à prendre une décision éclairée lorsqu'il est question de chirurgie.

$\mathbf{T}$ he prevalence of obesity has been increasing for the last 30 years, and obesity has been recognized as an epidemic by the World Health Organization. ${ }^{1}$ The prevalence of adult obesity in Canada is $20 \% .^{2}$ Currently, bariatric surgery is the most successful and most effective treatment for severe obesity in terms of weight loss, remission of comorbidities and improved quality of life. ${ }^{3}$

Bariatric surgery can be performed with low peri- and postoperative risk, including a 30-day mortality rate of $0.3 \%{ }^{4}$ Laparoscopy contributed substantially to the reduction in complications after bariatric surgery. ${ }^{5}$ A decade ago, older age was considered a relative contraindication to bariatric surgery. ${ }^{6}$ Advances in laparoscopic surgery and patient preoperative assessment have also contributed to decreased rates of postoperative complications and mortality.

To determine the factors that influence the infrequent peri- and postoperative adverse outcomes, a large standardized database of bariatric surgery outcomes is essential. The Ontario Bariatric Registry collects prospective data for all participating patients undergoing bariatric surgery in 11 bariatric centres across the province. Identifying independent factors that influence adverse events and bariatric surgical outcomes can lead to better patient selection and care, and better outcomes.

The aim of this study was to evaluate the relative influence of age and other factors on bariatric surgery outcomes in order to improve patient selection and outcomes.

\section{Methods}

\section{Design and setting}

The Ontario Bariatric Network maintains a prospective data registry, the Ontario Bariatric Registry, to record the preand postoperative outcomes of patients undergoing bariatric surgery at 10 Bariatric Centres of Excellence and 1 Regional Assessment and Treatment Centre in the province. Preoperative, operative and postoperative data are collected through chart review and patient questionnaire. The database registry is approved by the ethics committee at each participating centre, and all patients provide informed consent.

In Ontario, patients are referred through a centralized referral portal and assigned to a Bariatric Centre of Excellence or Regional Assessment and Treatment Centre based on their postal code. Currently, the 2 most common bariatric procedures performed are laparoscopic Roux-en-Y gastric bypass (LRYGB) and laparoscopic sleeve gastrec- tomy (LSG). In this retrospective study, we chose to include only patients who underwent 1 of these 2 operations.

\section{Study population}

This study included all registry patients aged 18 years or older who underwent LRYGB or LSG between January 2010 and May 2013.

\section{Covariables}

We selected the following independent variables, based on a review of the current literature: age, type of surgery, body mass index (BMI), gender, ethnicity, obstructive sleep apnea, previous myocardial infarction or angina, diabetes mellitus, hypertension, preoperative glycosylated hemoglobin $\left(\mathrm{HbA}_{\mathrm{lc}}\right)$ level and preoperative American Society of Anesthesiologists (ASA) score.

\section{Outcomes}

We defined two early outcomes (occurring within $90 \mathrm{~d}$ of surgery) and three 1-year outcomes. The first early outcome was a composite outcome based on the Longitudinal Assessment of Bariatric Surgery study. ${ }^{4}$ It included any of the following outcomes: deep vein thrombosis or pulmonary embolism, failure to discharge within 30 days, anastomotic or staple line leak, bleeding necessitating transfusion, reintervention, pulmonary complication (including pneumonia and respiratory failure, but not atelectasis), cardiac complication (including myocardial infarction, angina, heart failure or cardiac arrest), stroke and death. The second early outcome was readmission to hospital within 90 days of surgery.

The 1-year outcomes were 1) mean percent excess body weight loss (\%EBWL), which is widely used in the bariatric programs as an assessment tool; 2) remission of diabetes (defined as an $\mathrm{HbA}_{1 \mathrm{c}}$ level $<6.5 \%$ without antidiabetic medication); and 3) remission of hypertension (defined as systolic pressure $<140 \mathrm{~mm} \mathrm{Hg}$ and diastolic pressure $<90 \mathrm{~mm} \mathrm{Hg}$ without blood-pressure-lowering medication).

\section{Statistical analysis}

We calculated unadjusted odds ratios (ORs) for all independent variables. Associations were considered significant 
with a $p<0.05$. A multiple regression analysis was conducted to identify independent variables that control the main outcome measures. We conducted the DurbinWatson test to ensure independence of errors (residuals). We examined tolerance values and correlation coefficients to be fairly confident that we did not have an issue with collinearity in our data set. The assumptions of linearity, independence of errors, homoskedasticity, unusual points and normality of residuals were met before we interpreted the results. We performed analysis of variance to determine whether the regression model was a good fit for the data. We analyzed the data using SPSS Version 21.0 (IBM Corp.).

\section{Results}

We identified 3166 patients (2655 women [83.9\%] and 511 men [16.1\%] with a mean age of $44.8 \mathrm{yr}$ [standard deviation (SD) $10.3 \mathrm{yr}$ ) who underwent LRYGB or LSG between January 2010 and May 2013 and completed their 12-month follow-up (Table 1). Most patients (2839 [89.7\%]) underwent LRYGB. The mean BMI was 48.4 (SD 8.6). The rates of comorbidities of interest before surgery and 6 and 12 months after surgery are presented in Figure 1, and rates before and 12 months after surgery by procedure type are shown in Table 2. Remission of comorbidities at 1 year was significant except for obstructive sleep apnea after LSG.

The rate of intraoperative complications was $2.6 \%$. Most of the complications (56/82 [68\%]) were minor; there were no intraoperative deaths.

\section{Early outcomes}

Of the 3166 patients, 202 (6.4\%) were readmitted to hospital within 90 days. We excluded 250 patients from the composite outcome analysis because of missing data. Of the 2916 remaining patients, 34 (1.2\%) had sleeve or anastomosis stenosis, $18(0.6 \%)$ had an anastomotic leak, $12(0.4 \%)$ had pulmonary complications, $4(0.1 \%)$ had pulmonary embolism or deep vein thrombosis, $2(0.1 \%)$ had cardiac complications (myocardial infarction in 1 and angina pectoris in 1$)$, and $2(0.1 \%)$ were not discharged within 30 days, for a composite outcome of adverse events rate of $2.4 \%$. There were no occurrences of death or stroke.

Multiple regression analysis of the independent variables showed that previous angina and ASA score were

Table 1. Characteristics of patients who underwent LRYGB or LSG

\begin{tabular}{|c|c|}
\hline Characteristic & $\begin{array}{l}\text { No. (\%) of patients* } \\
n=3166\end{array}$ \\
\hline Age, mean \pm SD (range), yr & $44.8 \pm 10.3(19-72)$ \\
\hline Female sex & $2655(83.9)$ \\
\hline White ethnicity ( $n=2009$ ) & $1775(88.4)$ \\
\hline LRYGB & $2839(89.7)$ \\
\hline $\begin{array}{l}\text { Preoperative body mass index, mean } \pm \text { SD } \\
\text { (range) }\end{array}$ & $48.4 \pm 8.6(35.5-90.5)$ \\
\hline Preoperative ASA score, mean \pm SD & $3.17 \pm 0.5$ \\
\hline$\%$ EBWL at $1 \mathrm{yr}$, mean \pm SD & $60.43 \pm 16.3$ \\
\hline Taking prescribed medications ( $n=3162$ ) & $2818(89.1)$ \\
\hline \multicolumn{2}{|c|}{$\begin{array}{l}\text { ASA = American Society of Anesthesiologists; \%EBWL = percent excess body weight } \\
\text { loss; } L R Y G B=\text { laparoscopic Roux-en-Y gastric bypass; } L S G=\text { laparoscopic sleeve } \\
\text { gastrectomy; } S D=\text { standard deviation. } \\
\text { "Except where noted otherwise. }\end{array}$} \\
\hline
\end{tabular}

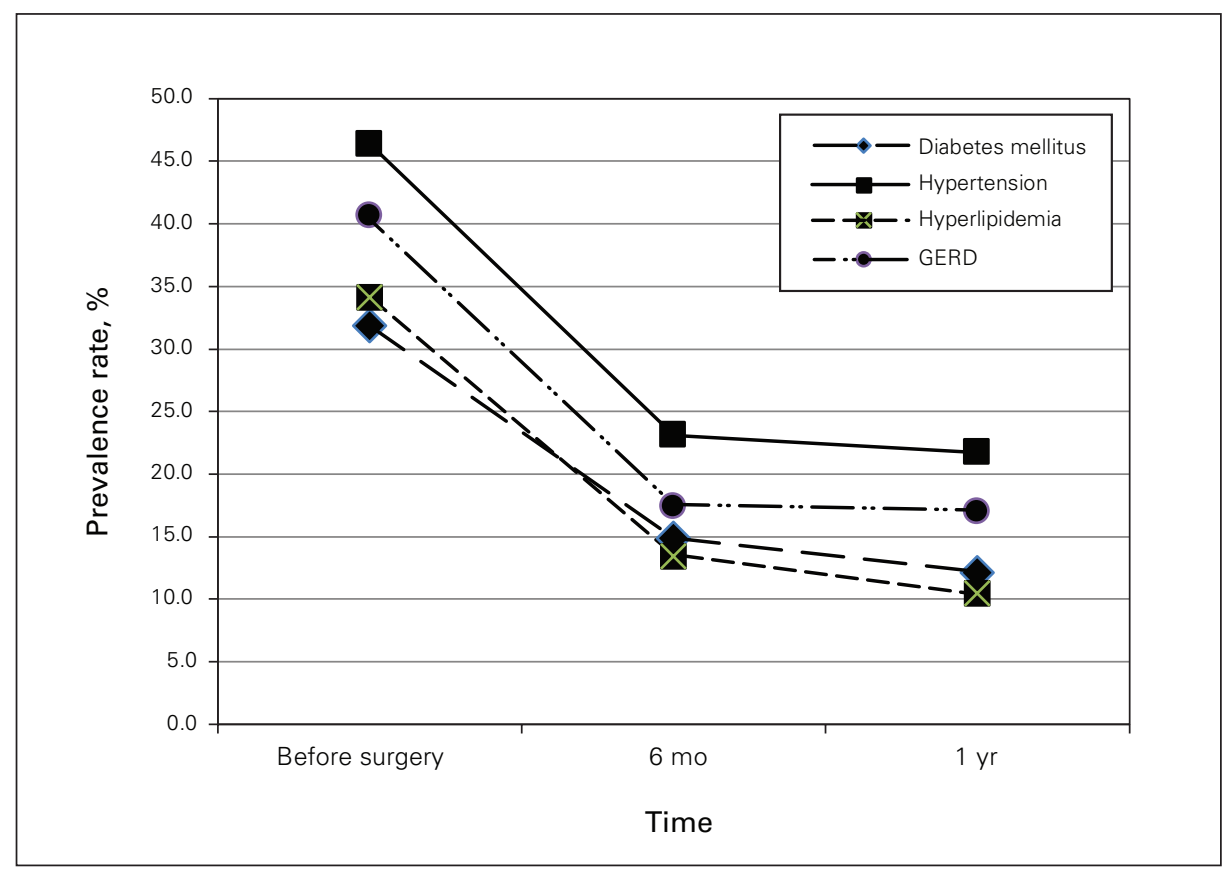

Fig. 1. Prevalence of comorbidities before surgery and 6 months and 1 year after surgery. $\mathrm{GERD}=$ gastroesophageal reflux disease. 


\begin{tabular}{|c|c|c|c|}
\hline \multirow{2}{*}{$\begin{array}{l}\text { Comorbidity; } \\
\text { procedure }\end{array}$} & \multicolumn{2}{|c|}{ No. (\%) of patients } & \multirow[b]{2}{*}{$p$ value } \\
\hline & Before surgery & $1 \mathrm{yr}$ & \\
\hline \multicolumn{4}{|c|}{ Diabetes mellitus } \\
\hline LRYGB & $879 / 2838(31.0)$ & 167/1484 (11.2) & $<0.001$ \\
\hline LSG & $128 / 327(39.1)$ & $32 / 156(20.5)$ & $<0.001$ \\
\hline \multicolumn{4}{|l|}{ Hypertension } \\
\hline LRYGB & $1282 / 2838(45.2)$ & 299/1484 (20.1) & $<0.001$ \\
\hline LSG & $186 / 327(56.9)$ & $57 / 156(36.5)$ & $<0.001$ \\
\hline \multicolumn{4}{|c|}{ Hyperlipidemia } \\
\hline LRYGB & 940/1894 (49.6) & 147/1337 (11.0) & $<0.001$ \\
\hline LSG & 139/327 (42.5) & 25/156 (16.0) & $<0.001$ \\
\hline \multicolumn{4}{|c|}{$\begin{array}{l}\text { Obstructive sleep } \\
\text { apnea }\end{array}$} \\
\hline LRYGB & $1138 / 2838(40.1)$ & $542 / 1483(36.5)$ & 0.02 \\
\hline LSG & $183 / 327(56.0)$ & $84 / 156$ (53.8) & 0.7 \\
\hline
\end{tabular}

\begin{tabular}{|c|c|}
\hline Variable & OR (95\% Cl) \\
\hline Age & 0.968 (0.928 to 1.009$)$ \\
\hline Male sex & 0.873 (0.285 to 2.677$)$ \\
\hline LRYGB & $1.222(0.337$ to 4.430$)$ \\
\hline White ethnicity & 0.0001 \\
\hline Aboriginal ethnicity & 1.1 (0.315 to 3.786$)$ \\
\hline Body mass index & 0.969 (0.918 to 1.023$)$ \\
\hline Glycosylated hemoglobin level & 0.990 (0.693 to 1.414$)$ \\
\hline Creatinine level & 0.995 (0.970 to 1.022$)$ \\
\hline Albumin level & $0.994(0.890$ to 1.110$)$ \\
\hline Angina & 3.584 (0.096 to 0.811$)$ \\
\hline Heart failure & $0.873(0.071$ to 9.814$)$ \\
\hline Myocardial infarction & 0.989 (0.104 to 9.423$)$ \\
\hline Diabetes mellitus & $1.303(0.443$ to 3.831$)$ \\
\hline Hypertension & $0.692(0.303$ to 1.582$)$ \\
\hline Obstructive sleep apnea & $0.541(0.241$ to 1.217$)$ \\
\hline ASA score & 2.588 (1.181 to 5.672 ) \\
\hline Constant & 0.178 \\
\hline
\end{tabular}

significantly associated with the occurrence of adverse postoperative events (Table 3 ).

Multiple regression analysis showed that diagnosis of obstructive sleep apnea preoperatively was significantly associated with readmission (Table 4). Age and type of surgery, however, were not predictive of any early outcomes.

\section{One-year outcomes}

The average 1-year \%EBWL was $60.43 \mathrm{~kg} / \mathrm{m}^{2}$ (SD $\left.16.3 \mathrm{~kg} / \mathrm{m}^{2}\right)$. The rates of diabetes, hypertension, hyper-

\begin{tabular}{|c|c|}
\hline Variable & OR $(95 \% \mathrm{Cl})$ \\
\hline Age & 0.980 (0.955 to 1.006$)$ \\
\hline Male sex & 0.781 (0.383 to 1.593$)$ \\
\hline LRYGB & 0.756 (0.384 to 1.487$)$ \\
\hline White ethnicity & 0.000 \\
\hline Aboriginal ethnicity & 1.411 (0.691 to 2.882 ) \\
\hline Body mass index & 0.993 (0.964 to 1.022$)$ \\
\hline $\begin{array}{l}\text { Glycosylated hemoglobin } \\
\text { level }\end{array}$ & $1.009(0.792$ to 1.285$)$ \\
\hline Creatinine level & 1.004 (0.991 to 1.018$)$ \\
\hline Albumin level & 1.011 (0.943 to 1.083$)$ \\
\hline Angina & 0.717 (0.286 to 1.795$)$ \\
\hline Heart failure & 1.474 (0.152 to 14.250$)$ \\
\hline Myocardial infarction & $0.423(0.115$ to 1.564$)$ \\
\hline Diabetes mellitus & 1.667 (0.807 to 3.444$)$ \\
\hline Hypertension & 0.339 (0.797 to 2.250$)$ \\
\hline Obstructive sleep apnea & 0.596 (0.363 to 0.977$)$ \\
\hline ASA score & 1.497 (0.913 to 2.454$)$ \\
\hline Constant & 0.067 \\
\hline
\end{tabular}

lipidemia, gastroesophageal reflux disease and obstructive sleep apnea were $12.1 \%$ (199/1639), 21.7\% (356/1639), $10.5 \%(172 / 1639), 17.0 \%(278 / 1638)$ and $38.2 \%(626 /$ 1638), respectively.

The independent variables found on multiple regression analysis to have a strong effect on \%EBWL were age, type of surgery, initial BMI and preoperative $\mathrm{HbA}_{1 \mathrm{c}}$ level. Younger patients had higher \%EBWL than older patients. Laparoscopic Roux-en-Y gastric bypass was found to be more effective than LSG in achieving weight loss. Patients with lower BMI had higher \%EBWL than those with higher BMI. Lower preoperative $\mathrm{HbA}_{1 \mathrm{c}}$ level was predictive of higher weight loss after bariatric surgery (Table 5). Lower preoperative $\mathrm{HbA}_{\mathrm{lc}}$ level (OR 1.30, 95\% confidence interval [CI 1.05 to 1.49 ) and diagnosis of obstructive sleep apnea (OR $0.57,95 \%$ CI 0.236 to 0.99 ) were strong predictors of diabetes remission. Age and surgery type influenced hypertension remission in the same way they influenced \%EBWL, with younger patients having a greater decrease in blood pressure values than older patients (OR 1.10, 95\% CI 1.02 to 1.11), and patients who underwent LRYGB showing greater weight loss than those who underwent LSG (OR 0.385, 95\% CI 0.186 to 0.790 ).

\section{Discussion}

In this study, the rate of adverse events in patients undergoing bariatric surgery was low. We used a composite outcome ${ }^{4}$ to perform a better analysis and found that $2.4 \%$ of patients experienced a composite outcome adverse event, which is comparable to rates reported in other studies. ${ }^{4,7}$ We separated readmission from the composite outcome 
Table 5. Factors predicting percent excess body weight loss 12 months after surgery

\begin{tabular}{|lcc|}
\hline Factor & $\begin{array}{c}\text { Unstandardized } \beta \\
\text { coefficient (SE) }\end{array}$ & $\begin{array}{c}\text { Standardized } \beta \text { coefficient } \\
(95 \% \text { Cl) }\end{array}$ \\
\hline Constant & $78.24(17.242)$ & $(44.369$ to 112.120$)$ \\
\hline Age & $-0.44(0.080)$ & $-0.243(-0.596$ to -0.281$)$ \\
\hline LRYGB & $-3.80(0.706)$ & $-0.225(-5.192$ to -2.417$)$ \\
\hline Body mass index & $-0.51(0.093)$ & $0.244(-0.690$ to -0.323$)$ \\
\hline Sex & $-1.54(2.117)$ & $0.032(-5.696$ to 2.624$)$ \\
\hline Ethnicity & $-1.39(1.263)$ & $0.044(-3.877$ to 1.086$)$ \\
\hline $\begin{array}{l}\text { Obstructive sleep } \\
\text { apnea }\end{array}$ & $1.265(1.491)$ & $0.036(-1.664$ to 4.195$)$ \\
\hline Angina & $1.590(3.024)$ & $0.021(4.351$ to 7.531$)$ \\
\hline Heart failure & $7.232(8.067)$ & $0.037(-8.618$ to 23.081$)$ \\
\hline Myocardial infarction & $10.02(7.008)$ & $0.057(-3.747$ to 23.791$)$ \\
\hline Diabetes mellitus & $1.337(1.982)$ & $0.036(-2.557$ to 5.230$)$ \\
\hline Hypertension & $0.259(1.533)$ & $0.008(-2.752$ to 3.271$)$ \\
\hline $\begin{array}{l}\text { Glycosylated } \\
\text { hemoglobin level }\end{array}$ & $-2.23(0.677)$ & $-0.176(-3.568$ to -0.907$)$ \\
\hline Creatinine level & $0.001(0.034)$ & $0.002(-0.066$ to 0.068$)$ \\
\hline Albumin level & $0.511(0.200)$ & $0.107(0.118$ to 0.903$)$ \\
\hline ASA score & $1.870(1.595)$ & $0.052(-1.264$ to 5.004$)$ \\
\hline $\begin{array}{l}\text { ASA = American Society of Anesthesiologists; Cl }=\text { confidence interval; LRYGB }= \\
\text { laparoscopic Roux-en-Y gastric bypass; SE = standard error. }\end{array}$ \\
\hline
\end{tabular}

because of the difficulty in defining the cause for readmission. We found that a previous history of angina and high ASA score were independent factors that negatively influenced the occurrence of adverse events after bariatric surgery. Wolter and colleagues ${ }^{10}$ also found that ASA score was a predictor of postoperative outcome.

The ASA score has been shown to have high variability, even within the same institution. ${ }^{11,12}$ Although the ASA score is used worldwide, this limitation highlights the need to consider standardization and use of more objective measurements. However, the significant correlation between ASA score and the composite outcome in the present study justifies its use until a more accurate assessment tool is developed. Finks and colleagues ${ }^{13}$ showed a relation between coronary artery disease and increased complications after bariatric surgery. We found a significant correlation between the two, which may highlight the importance of cardiac assessment before bariatric surgery.

There is great variability in the causes for readmission after bariatric surgery. The 90-day readmission rate in our study was $6.4 \%$, comparable to that in other published studies, with reported 30-day readmission rates of up to $15 \% .{ }^{14,15}$ Nausea or vomiting causing fluid, electrolyte or nutrient deficiency was identified by Berger and colleagues $^{16}$ as the main cause for readmission (35.4\%). Unlike Sun and colleagues, ${ }^{17}$ who found multiple factors related to readmission (including initial BMI, higher ASA score and history of cardiac disease), we found that only a prior history of obstructive sleep apnea was associated with readmission. The Longitudinal Assessment of Bariatric Surgery study showed that obstructive sleep apnea was related to increased risk of adverse events after bariatric surgery. ${ }^{4}$ Although we did not find this relation, the fact that obstructive sleep apnea was related to perioperative adverse events could be inferred from the observed association with readmission. Dorman and colleagues ${ }^{18}$ reported that patients with obstructive sleep apnea had significantly higher odds of being readmitted within 30 days compared to those without obstructive sleep apnea (OR 1.5, 95\% CI 1.1 to 1.9$)$. This observation was limited to patients who underwent adjustable gastric banding and was not found in those who had LRYGB. Further study is needed on this subject.

Prognostic factors that influence \%EBWL after bariatric surgery have been reviewed. ${ }^{19,20}$ Our results support those of the SLEEVEPASS study, in which 240 patients with severe obesity were followed. ${ }^{21}$ The investigators concluded that patients who had undergone LRYGB had greater \%EBWL than those who had undergone LSG, but the difference was not statistically significant. In a Swiss multicentre randomized trial of 217 obese patients, there was no significant difference in weight loss at 1,2 or 5 years between the LRYGB and LSG groups. ${ }^{22}$ The negative correlation of age, initial $\mathrm{BMI}$ and preoperative $\mathrm{HbA}_{1 \mathrm{c}}$ level on \%EBWL is well established..$^{20,23,24}$ At our institute, LSG is offered to patients with higher initial BMI or a history of multiple abdominal surgical procedures, and on patient request. The higher initial BMI may explain the negative correlation between initial $\mathrm{BMI}$ and \%EBWL in this group.

Bariatric surgery is superior to conventional medical therapy for the treatment and remission of diabetes mellitus in obese patients. ${ }^{25}$ In our study, diabetes remission was defined as an $\mathrm{HbA}_{\mathrm{lc}}$ level less than $6.5 \%$ and no use of antidiabetic medications. The severity of disease, which correlates to higher $\mathrm{HbA}_{1 \mathrm{c}}$ level and use of several medications for glycemic control, has been reported to have a negative influence on the chances of remission after bariatric surgery. ${ }^{26}$ Similarly, we found that a low $\mathrm{HbA}_{\mathrm{cc}}$ level preoperatively may predict remission of diabetes 1 year after bariatric surgery, which is in agreement with current literature. ${ }^{27}$

We found a direct negative relation between obstructive sleep apnea and diabetes remission after bariatric surgery. This association is well established. ${ }^{28}$ Decreased insulin sensitivity in patients with obstructive sleep apnea seems to be the factor in this association. ${ }^{29}$

Remission of hypertension after bariatric surgery has been less well studied than diabetes remission after bariatric surgery. We defined hypertension remission as a systolic blood pressure less than $140 \mathrm{~mm} \mathrm{Hg}$ and diastolic blood pressure less than $90 \mathrm{~mm} \mathrm{Hg}$ with the patient not taking any antihypertensive medications and found that patients who had LRYGB were more likely than those who underwent LSG to be cured of hypertension. Flores and colleagues $^{30}$ reported that patients with a long ( $\geq 10 \mathrm{yr}$ ) history of hypertension or taking multiple antihypertensive 
medications $(\geq 3)$ were less likely to be cured than patients receiving fewer than 3 medications. Zhang and colleagues ${ }^{31}$ reported no difference in blood pressure reduction between procedures (LRYGB v. LSG) at postoperative day $30(23.5 \%$ v. $22.5 \%), 6$ months $(40 \%$ v. $39.2 \%)$ or 1 year $(52.9 \%$ v. $38.8 \%)$. Although the difference in the remission rate was higher in the LRYGB group, the difference was not statistically significant. Studies describing health benefits of gastric bypass have shown hypertension remission or blood pressure reduction of $50 \%-60 \%$ at 2 years across all surgical procedures. ${ }^{32,33}$ We believe that if the duration of outcome assessment had been extended in the studies that showed higher but statistically nonsignificant hypertension remission rates, the impact of type of surgery would have been apparent.

The correlation between age and bariatric surgery outcomes is unclear. Although increased age was once a relative contraindication for bariatric surgery and was shown to be a prognostic factor for complications,${ }^{34}$ recent literature shows that bariatric surgery is effective and safe in older patients. ${ }^{23,35} \mathrm{We}$ did not find any correlation between age and adverse events or readmission after bariatric surgery. The effect of age on remission of obesity-related comorbidities is not well defined. In the present study, age was a significant factor in hypertension remission but not diabetes remission.

\section{Limitations}

The duration of follow-up for this study was only 1 year. Preoperative disease definition and the clinical decision to start, change or stop the use of medication was not standardized. Despite these limitations, this study showed comparable results to those of other studies in regard to preoperative comorbidity prevalence, \%EBWL and remission of obesity-related comorbidities. Follow-up was based on patient questionnaire, which may be subject to information bias or misclassification. ${ }^{36}$

\section{Conclusion}

Using a large standardized database, we identified prognostic factors that influence outcomes and complications after bariatric surgery. Higher ASA score (although not well standardized) and a history of angina were independently related to postoperative complications. Age seemed to be a less significant factor in risk assessment and outcomes. Knowledge of factors predictive of outcomes and complications after bariatric surgery should help both the surgeon and the patient to make the appropriate decision regarding surgery.

Affiliations: From the Department of General Surgery B, Emek Medical Center, Afula, Israel (Kaplan); the Faculty of Medicine, Cairo University, Cairo, Egypt (Zohdy); and the Department of Surgery, McMaster University, Hamilton, Ont. (Gmora, Hong, Anvari).
Competing interests: None declared.

Contributors: U. Kaplan and M. Anvari designed the study. S. Gmora and M. Anvari acquired the data, which W. Zohdy, D. Hong and M. Anvari analyzed. U. Kaplan and W. Zohdy wrote the manuscript, which S. Gmora, D. Hong and M. Anvari critically revised. All authors gave final approval of the article to be published.

Content licence: This is an Open Access article distributed in accordance with the terms of the Creative Commons Attribution (CC BY-NCND 4.0) licence, which permits use, distribution and reproduction in any medium, provided that the original publication is properly cited, the use is noncommercial (i.e., research or educational use), and no modifications or adaptations are made. See: https://creativecommons.org/licenses/by -nc-nd/4.0/

\section{References}

1. Obesity: preventing and managing the global epidemic. Report of a WHO consultation. World Health Organ Tech Rep Ser 2000;894:i-xii, $1-253$.

2. Aguilar M, Bhuket T, Torres S et al. Prevalence of the metabolic syndrome in the United States. FAMA 2015;313:1973-4.

3. Dorman RB, Abraham AA, Al-Refaie WB, et al. Bariatric surgery outcomes in the elderly: an ACS NSQIP study. 7 Gastrointest Surg 2012;16:35-44.

4. The Longitudinal Assessment of Bariatric Surgery (LABS) Consortium; Flum DR, Belle SH, King WC, et al. Peri-operative safety in the longitudinal assessment of bariatric surgery. N Engl 7 Med 2009; 361:445-54.

5. Tian HL, Tian JH, Yang KH, et al. The effects of laparoscopic vs. open gastric bypass for morbid obesity: a systematic review and meta-analysis of randomized controlled trials. Obes Rev 2011;12: 254-60.

6. Valera JE, Wilson SENN. Outcomes of bariatric surgery in the elderly. Am Surg 2006;72:865-9.

7. Aminian A, Brethauer SA, Sharafkhah M, et al. Development of a sleeve gastrectomy risk calculator. Surg Obes Relat Dis 2015;11: 758-64.

8. Daigle CR, Brethauer SA, Tu C, et al. Which postoperative complications matter most after bariatric surgery? Prioritizing quality improvement efforts to improve national outcomes. Surg Obes Relat Dis 2018;14:652-7.

9. Fridman A, Moon R, Cozacov Y, et al. Procedure-related morbidity in bariatric surgery: a retrospective short- and mid-term followup of a single institution of the American College of Surgeons Bariatric Surgery Centers of Excellence. 7 Am Coll Surg 2013;217: 614-20.

10. Wolters U, Wolf T, Stutzer HST. ASA classification and perioperative variables as predictors of postoperative outcome. Br 7 Anaesth 1996;77:217-22.

11. Mak PH, Campbell RC, Irwin MG. The ASA Physical Status Classification: inter-observer consistency. Anaesth Intensive Care 2002;30: 633-40.

12. Haynes SR, Lawler PGP. An assessment of the consistency of ASA Physical Status Classification allocation. Anaesthesia 1995;50:195-9.

13. Finks JF, Kole KL, Yenumula PR, et al.; Michigan Bariatric Surgery Collaborative, from the Center for Healthcare Outcomes and Policy. Predicting risk for serious complications with bariatric surgery: results from the Michigan Bariatric Surgery Collaborative. Ann Surg 2011;254:633-40.

14. Garg T, Rosas U, Rogan D, et al. Characterizing readmissions after bariatric surgery. 7 Gastrointest Surg 2016;20:1797-801. 
15. Major P, Wysocki M, Torbicz G, et al. Risk factors for prolonged length of hospital stay and readmissions after laparoscopic sleeve gastrectomy and laparoscopic Roux en-Y gastric bypass. Obes Surg 2018; $28: 323-32$.

16. Berger ER, Huffman KM, Fraker T, et al. Prevalence and risk factors for bariatric surgery readmissions: findings from 130,007 admissions in the Metabolic and Bariatric Surgery Accreditation and Quality Improvement Program. Ann Surg 2018;267:122-31.

17. Sun SX, Hollenbeak CS, Rogers AM. Readmissions following gastric bypass surgery. Obes Surg 2016;26:269-75.

18. Dorman RB, Miller CJ, Leslie DB, et al. Risk for hospital readmission following bariatric surgery. PLoS One 2012;7:e32506.

19. Ortega E, Morínigo R, Flores L, et al. Predictive factors of excess body weight loss 1 year after laparoscopic bariatric surgery. Surg Endosc 2012;26:1744-50.

20. Still CD, Wood GC, Chu X, et al. Clinical factors associated with weight loss outcomes after Roux-en-Y gastric bypass surgery. Obesity (Silver Spring) 2014;22:888-94.

21. Salminen P, Helmiö M, Ovaska J, et al. Effect of laparoscopic sleeve gastrectomy vs laparoscopic roux-en-Y gastric bypass on weight loss at 5 years among patients with morbid obesity: the SLEEVEPASS randomized clinical trial. FAMA 2018;319:241-54.

22. Peterli R, Borbély Y, Kern B, et al. Early results of the Swiss Multicentre Bypass or Sleeve Study (SM-BOSS): a prospective randomized trial comparing laparoscopic sleeve gastrectomy and Roux-en-Y gastric bypass. Ann Surg 2013;258:690-5.

23. Kaplan U, Penner S, Farrokhyar F, et al. Bariatric surgery in the elderly is associated with 320 similar surgical risks and significant long-term health benefits. Obes Surg 2018;28:2165-70.

24. Ochner CN, Jochner MC, Caruso EA, et al. Effect of preoperative body mass index on weight loss following obesity surgery. Surg Obes Relat Dis 2013;9:423-7.
25. Mingrone G, Panunzi S, De Gaetano A, et al. Bariatric surgery versus conventional medical therapy for type 2 diabetes. $N$ Engl 7 Med 2012;366:1577-85.

26. Hatoum IJ, Blackstone R, Hunter TD, et al. Clinical factors associated with remission of obesity-related comorbidities after bariatric surgery. FAMA 2016;151:130-7.

27. Robert M, Ferrand-Gaillard C, Disse E, et al. Predictive factors of type 2 diabetes remission 1 year after bariatric surgery: impact of surgical techniques. Obes Surg 2013;23:770-5.

28. Nannapaneni S, Ramar K, Surani S. Effect of obstructive sleep apnea on type 2 diabetes mellitus: a comprehensive literature review. World 7 Diabetes 2013;4:238-44.

29. Song SO, He K, Narla RR, et al. Metabolic consequences of obstructive sleep apnea especially pertaining to diabetes mellitus and insulin sensitivity. Diabetes Metab f 2019;43:144-55.

30. Flores L, Vidal J, Canivell S, et al. Hypertension remission 1 year after bariatric surgery: predictive factors. Surg Obes Relat Dis 2014;10:661-5.

31. Zhang N, Maffei A, Cerabona T, et al. Reduction in obesity-related comorbidities: Is gastric bypass better than sleeve gastrectomy? Surg Endosc 2013;27:1273-80.

32. Adams TD, Davidson LE, Litwin SE, et al. Health benefits of gastric bypass surgery after 6 years. FAMA 2012;308:1122-31.

33. Sjöström CD, Peltonen M, Wedel H, et al. Differentiated long-term effects of intentional weight loss on diabetes and hypertension. Hypertension 2000;36:20-5.

34. Scozzari G, Passera R, Benvenga R, et al. Age as a long-term prognostic factor in bariatric surgery. Ann Surg 2012;256:724-8.

35. Chow A, Switzer NJ, Gill RS, et al. Roux-en-Y gastric bypass in the elderly: a systematic review. Obes Surg 2016;26:626-30.

36. Althubaiti A. Information bias in health research: definition, pitfalls, and adjustment methods. 7 Multidiscip Healthc 2016;9:211-7. 